\title{
Left Ventricular Noncompaction
}

\author{
Malla R, ${ }^{1}$ Sharma R, ${ }^{1}$ Rauniyar B, ${ }^{1}$ K.C MB, ${ }^{1}$ Maskey A, Joshi D, ${ }^{1}$ Hamal S ${ }^{1}$ \\ 'Department of Cardiology, Shahid Gangalal National Heart Center, Bansbari, Kathmandu, Nepal
}

\section{ABSTRACT}

Left Ventricular Noncompaction(LVNC) is a genetic cardiac disease of emerging importance with a distinct clinical and pathophysiological presentation. The most common clinical manifestations include heart failure, arrhythmias and embolic events, and in children it may be associated with facial dysmorphisms and Wolff-Parkinson-White syndrome. The diagnosis of LVNC, however, is often missed, most often as a consequence of ignorance of the condition. Echocardiography is considered the reference standard for the diagnosis of LVNC. Prognosis remains poor for patients with impaired systolic left ventricular function, as treatment options are very limited. Because of the familial association of LVNC, first-degree relatives should be screened by Echocardiography.

Key Words: heart, left ventricle, noncompaction

\section{INTRODUCTION}

The persistence of prominent myocardial trabeculation, although seen in the normal right ventricle, does not usually occur after birth in the left ventricle. ${ }^{1}$ During the early embryonic phase, the left ventricular myocardium consists of a loose network of fibres separated by deep recesses that link the myocardium with the left ventricular cavity. Gradual compaction of these fibres and intertrabecular recesses usually occurs within 8 weeks of life, progressing from the epicardium to endocardium and from the base of the heart to the apex. ${ }^{1}$

LVNC is a rare congenital cardiomyopathy, caused by intrauterine arrest of compaction of the myocardial fibers and meshwork. ${ }^{2}$ LVNC is characterized by a distinctive ("spongy") morphological appearance of the LV myocardium. ${ }^{3}$ Noncompaction involves predominantly the apical portion of the LV chamber with deep intertrabecular recesses (sinusoids) in communication with the ventricular cavity. ${ }^{4}$ LVNC may be an isolated finding or may be associated with other congenital heart anomalies such as complex cyanotic congenital heart disease. ${ }^{5}$

\section{HISTORY}

LVNC was first described in the case of 33 year old woman in 1984, assessed by two-dimensional echocardiography. ${ }^{6}$ In 1985 a 21-year old female patient who first experienced an episode of acute left heart failure at the age of 15, who had undergone left ventricular angiography showed a honeycomb-like structure of the inner left ventricular wall and diagnosed as LVNC. $^{7}$ In 1986 a 21 -year-old male student who 
died of acute left heart failure, an autopsy proved for the first time the diagnosis of persistent sinusoids, today called LVNC. . $^{89}$

\section{CLASSIFICATION OF CARDIOMYOPATHY}

The 1995 report of the World Health Organization and of the International Society and Federation of Cardiology Task Force on the Definition and Classification of Cardiomyopathies, LVNC remains in the category of unclassified cardiomyopathies. ${ }^{10}$ Recently published Contemporary Definitions and Classification of the cardiomyopathies, LVNC remains in the category of genetic cardiomyopathy. ${ }^{11}$

\section{WHO Classification of cardiomyopathies}

1. Dilated cardiomyopathy

2. Hypertrophic cardiomyopathy

3. Restrictive cardiomyopathy

4. Arrhythmogenic right ventricular cardiomyopathy

5. Unclassified cardiomyopathies.

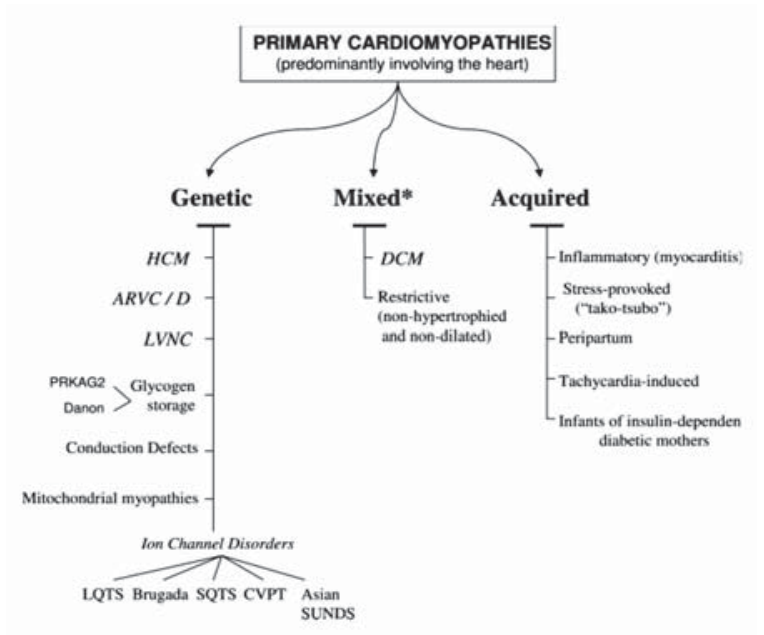

Figure 1. Contemporary Definitions and Classification of the Cardiomyopathies-2006 ${ }^{1}$

\section{PREVALENCE}

The prevalence of LVNC is not well known and there has been a scarcity of population-based studies of LVNC. In largest series it has been reported from $0.014 \%$ to $0.05 \% .{ }^{12}$ A retrospective cohort study of primary cardiomyopathy in Australian children, LVNC accounted for $9.2 \%$ of all cases, identified as the third most frequent cardiomyopathy after dilated and hypertrophic cardiomyopathies and based on this study the prevalence of LVNC among children 0-10 years of age was 0.12 per $100,000 . .^{13}$ In the largest series of adult patients with LVNC, Oechslin et al reported that prevalence was $0.014 \%$ in patients referred to the echocardiography laboratory. ${ }^{14}$ LVNC can affect any age group and review of the literature show a slight excess of males with male proportion ranging from $56 \%$ to $82 \% .{ }^{15,16}$

\section{ETIOLOGY}

LVNC is a genetically heterogeneous disorder. ${ }^{17}$ Both familial and nonfamilial forms have been described. Familial recurrence was seen in $18 \%$ in the largest reported adult population with LVNC. ${ }^{18}$ In the isolated form of LVNC, ZASP (Z-line) and mitochondrial mutations and $X$-linked inheritance resulting from mutations in the G4.5 gene encoding tafazzin (including association with Barth syndrome in neonates) have been reported. ${ }^{19,20}$ But noncompaction associated with congenital heart disease has been shown to result from mutations in the dystrobrevin gene and transcription factor NKX2.5. ${ }^{21}$

Adult forms of LVNC are genetically distinct from $X$ linked infantile cases in that mutations in the $G 4.5$ gene were not found to be the underlying mechanism. They are suggested to be transmitted by an autosomal dominant trait. ${ }^{22}$ The adult LVNC population described by Sasse-Klaassen et al had no typical signs of Barth syndrome. Interestingly, familial recurrence seems to be more common in adult patients with LVNC than in paediatric populations. ${ }^{23}$

\section{CLINICAL MANIFESTATIONS}

The major clinical manifestations in patients with LVNC with reduced systolic left ventricular function are 1. Heart failure 2. Arrhythmias 3. Systemic embolic events. ${ }^{24}$

The diagnosis of LVNC was often delayed; in the cohort presented by Ritter et al, the mean time elapsed from onset of symptoms to correct diagnosis was 3.5 (5.7) years. ${ }^{25}$

In the cohort with LVNC described in the initial report by Chin et al depressed ventricular systolic function was noted in $63 \%$ of patients. ${ }^{7}$ In a population of Japanese children with LVNC followed for up to 17 years, left ventricular dysfunction developed in the vast majority, regardless of the presence or absence of symptoms at initial diagnosis. ${ }^{22}$

Arrhythmias are common in patients with LVNC. ${ }^{26}$ Atrial fibrillation has been reported in over $25 \%$ of adults with LVNC. ${ }^{25}$ Ventricular tachyarrhythmias have been reported in as many as $47 \% .{ }^{27}$ Sudden cardiac death accounted for half of the deaths in the larger series of patients with LVNC. ${ }^{14}$ Ventricular arrhythmias occurred in nearly $40 \%$ of patients in the initial description of LVNC by Chin et al. ${ }^{7}$ Paroxysmal supraventricular tachycardia and complete heart block have also been 
reported in patients with LVNC $^{22}$ Oechslin et al ${ }^{14}$ described left bundle branch block in $44 \%$ of adult patients with LVNC. Electrocardiographic findings of the Wolff-Parkinson-White syndrome have been described in up to $15 \%$ of pediatric patients. ${ }^{28}$

The occurrence of thromboembolic events, including cerebrovascular accidents, transient ischemic attacks, pulmonary embolism, and mesenteric infarction, ranged from $21 \%$ to $38 \% .{ }^{29}$ Embolic complications may be related to development of thrombi in the extensively trabeculated ventricle, depressed systolic function, or the development of atrial fibrillation. ${ }^{30}$ An association between noncompaction and neuromuscular disorders has also been described with as many as $82 \%$ of patients having some form of neuromuscular disorder. ${ }^{31}$

In a more recent publication, long-term follow up of 34 adult patients was reported by Oechslin et al, ${ }^{14}$ Twentyfive $(74 \%)$ patients were men, with a mean age at diagnosis of 42 (17) years. The most common reason for referral was heart failure in 21 patients $(62 \%)$, followed by uncertain echocardiographic findings in $4(12 \%)$ and palpitations in 2 patients $(6 \%)$. Twenty seven patients (79\%) presented with shortness of breath, with 22 patients $(65 \%)$ being in New York Heart Association class I and II, and 12 patients (35\%) being in class III and IV. Most patients (94\%) had an abnormal ECG, with left bundle branch block being the most common abnormality (in $44 \%$ of the patients). Six (18\%) patients had familial occurrence.

Lofiego et al studied 65 patients with LVNC and were followed up for 6-193 months (mean 46 (SD 44). In 53 (82\%) patients, LVNC was associated with variable degrees of left ventricular (LV) dilatation and hypokinesia, and in the remaining $12(18 \%)$ LV volumes were normal. Diagnosis was symptom based in 48 $(74 \%)$ and non-symptom based in 17 (26\%). ${ }^{24}$ The non-symptom-based subgroup was characterised by younger age, lower prevalence of ECG abnormalities, better systolic function and lower left atrial size, whereas the extent of non-compaction was not different. No major cardiovascular events occurred in the non-symptombased group, whereas 15 of 48 (31\%) symptomatically diagnosed patients experienced cardiovascular death or heart transplantation $(\mathrm{p}=$ $0.01)$

\section{DIAGNOSIS}

Diagnosis is made with 2-dimensional Echocardiography, cardiac magnetic resonance imaging, or LV angiography.

${ }^{32}$ Echocardiography is considered the reference standard for the diagnosis of LVNC. ${ }^{33-35}$ Echocardiographic diagnostic criteria for LVNC included. ${ }^{36}$

1. Absence of coexisting cardiac abnormalities (other than 2-4) by definition.
2. Typical two-layered structure of the myocardium with a thin, compacted outer (epicardial) band and a much thicker, non-compacted inner (endocardial) layer consisting of trabecular meshwork with deep endocardial spaces (the maximum end systolic ratio of the non-compacted endocardial layer to the compacted myocardium of $>2$ is characteristic).

3. Predominant segmental location of the abnormality (that is, noncompacted myocardium is predominantly $(>80 \%)$ found in the apical and mid-ventricular areas of both the inferior and the lateral wall).

4. Colour Doppler echocardiographic evidence of deeply perfused intertrabecular recesses (in contrast to myocardial sinusoids, intertrabecular spaces do not communicate with the coronary circulation.
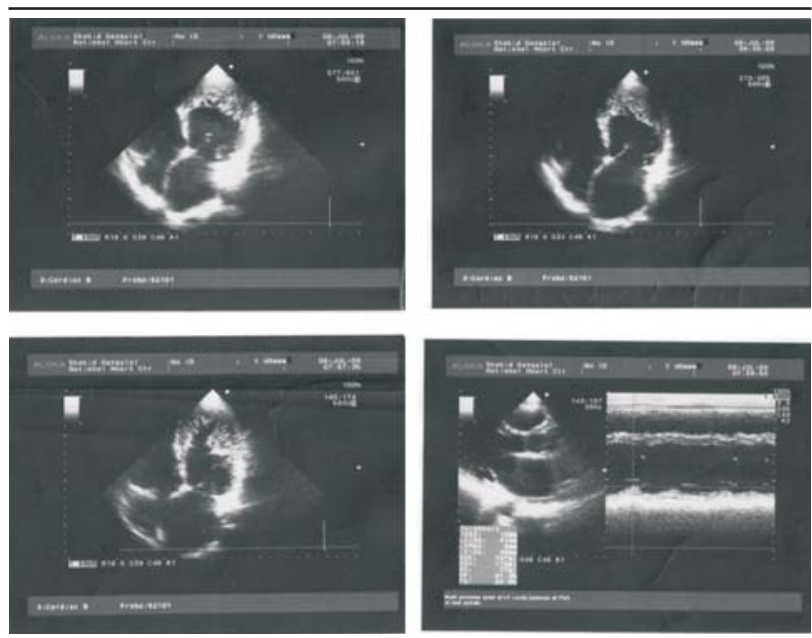

Figure2. TTE of a 49 years old male with LVNC

Cardiac MRI also has a role in the diagnosis, and can provide convincing evidence. ${ }^{37-38}$ MRI clearly has potential, especially in patients for whom good echocardiographic quality cannot be obtained. ${ }^{39-42}$ Another potential advantage of MRI is the possibility of identifying subendocardial perfusion deficits. ${ }^{43,44}$ The CMR diagnostic criteria for LVNC included. ${ }^{45}$

1. The visual appearance of two distinct myocardial layers; a compacted epicardial layer and a noncompacted endocardial layer.

2. The presence of marked trabeculation and deep intertrabecular recesses within the non-compacted layer.

3. A non-compacted to compacted myocardial ratio of $>2.3$ as measured in end diastole in the long axis views.

4. The absence of other associated cardiac abnormalities.

LV Angiography the typical features of LVNC have also been observed by ventriculography. ${ }^{46}$ After injection of contrast medium, a "honeycomb-like" or "loosened" 
structure of the inner left ventricular myocardium can be identified. However, a left ventricular angiogram and coronary angiography are usually performed to rule out other concomitant cardiac abnormalities and not for the diagnosis of LVNC.

\section{TREATMENT OPTIONS}

Management of patients with LVNC is similar to that of patients with other cardiomyopathies and should therefore include appropriate treatment for heart failure, management of arrhythmias and oral anticoagulation to prevent systemic emboli in patients with impaired left ventricular function. ${ }^{47}$ Standard medical therapy for systolic and diastolic ventricular dysfunction is warranted. The beneficial effects of the ß-blocker carvedilol on left ventricular function, mass, and neurohormonal dysfunction in an infant with LVNC have been described. ${ }^{48}$ Cardiac transplantation has been used for those with refractory congestive heart failure. ${ }^{49,50}$ Implantation of an internal cardioverter defibrillator system has seriously to be considered. Prevention of embolic complications is also an important management issue, and several authors have recommended longterm prophylactic anticoagulation for all patients with ventricular noncompaction whether or not thrombus has been found. Because of the familial association described with noncompaction, screening echocardiography of first degree relatives is recommended. Given the high percentage of associated neuromuscular disorders reported in patients with LVNC, neurological and musculoskeletal evaluations are also recommended.

\section{PROGNOSIS}

During the 6 year follow-up period of patients in the study by Ritter et al, ${ }^{25} 8$ of 17 patients died (three of them had a sudden cardiac death) and two underwent heart transplantation. In a larger series of patients, longterm follow up 44 months showed that $35 \%$ died, half of them because of sudden cardiac death, and $12 \%$ (four patients) had undergone heart transplantation. ${ }^{14}$ The high incidence of both thromboembolic events $(24 \%)$ and ventricular tachycardia $(41 \%)$ in that series underscores the poor clinical prognosis for patients with impaired left ventricular function. ${ }^{22}$ Because of the generally poor prognosis and because of the familial association of LVNC, first-degree relatives should be screened by echocardiography. ${ }^{51}$

\section{CONCLUSION}

LVNC is a genetic cardiac disease of emerging importance with a distinct clinical and pathophysiological presentation. As illustrated by numerous case reports and recent observational studies, IVNC has become an increasingly recognised cause of heart failure and other clinical cardiac manifestations in adults. The diagnosis of LVNC, however, is often missed, most often as a consequence of ignorance of the condition. Echocardiography is considered the reference standard for the diagnosis of LVNC. Prognosis remains poor for patients with impaired systolic left ventricular function, as treatment options are very limited. Because of the familial association of LVNC, first-degree relatives should be screened by Echocardiography

\section{REFERENCES}

1. Sedmera D, Pexieder T, Vuillemin M. Developmental patterning of the myocardium. Anat Rec. 2000; 258:319-37.

2. Finsterer J, Stollberger C, Feichtinger H. Histological appearance of left ventricular hypertrabeculation/ noncompaction. Cardiology. 2002;90:899-902.

3. Shah P, Nagi KS, Thakur RK. Spongy left ventricular myocardium in an adult. Tex Heart Inst J. 1998;25:150-1.

4. Dusek J, Ostadal B, Duskova M. Postnatal persistence of spongy myocardium with embryonic blood supply. Arch Pathol. 1975;99:312-7.

5. Zaragoza MV, Arbustini E, Narula J. Noncompaction of the left ventricle: primary cardiomyopathy with an elusive genetic etiology. Curr Opin Pediatr. 2007;19:619.

6. Freedom RM, YooSJ, Perrin D. The morphological spectrum of ventricular noncompaction. Cardiol Young. 2005;15:345-64.

7. Chin TK, Perloff JK, Williams RG. Isolated noncompaction of left ventricular myocardium: a study of eight cases. Circulation.1990;82:507-13.

8. Finsterer J, Stollberger C, Feichtinger H. Histological appearance of left ventricular hypertrabeculation/ noncompaction. Cardiology. 2002;90:899-902.
9. Jenni R, Goebel N, Tartini R. Persisting myocardial sinusoids of both ventricles as an isolated anomaly: echocardiographic, angiographic, and pathologic anatomical findings. Cardiovasc Intervent Radiol. 1986;9:127-31.

10. Richardson P, McKenna W, Bristow M. Report of the 1995 World Health Organization/ International Society and Federation of Cardiology task Force on the Definition and ClassificationofCardiomyopathies. Circulation.1996;93:841-2.

11. Maron BJ, Towbin JA, Thiene G . Contemporary Definitions and Classification of the Cardiomyopathies: Circulation. 2006;113;1807-16.

12. Pignatelli RH, McMahon CJ, Dreyer WJ. Clinical characterization of left ventricular noncompaction in children: a relatively common form of cardiomyopathy. Circulation. 2003;108:2672.

13. Nugent AW, Daubeney PEF, Chondros P. The epidemiology of childhood cardiomyopathy in Australia. N Engl J Med. 2003;348:1639-46.

14. Oechslin EN, Attenhofer-Jost C, Rojas JR. Long-term follow-up of 34 adults with isolated left ventricular noncompaction: a distinct cardiomyopathy with poor prognosis. J Am Coll Cardiol. 2000;36:493-500. 
15. Pignatelli RH, McMahon CJ, Dreyer WJ. Clinical characterization of left ventricular noncompaction in children. Circulation. 2003;108:2672-8.

16. Weiford BC, Subbarao VD, Mulhern KM. Noncompaction of the ventricular myocardium. Circulation. 2004;109:2965-71.

17. Xing Y, Ichida F, Matsuoka T. Genetic analysis in patients with left ventricular noncompaction and evidence for genetic heterogeneity. Mol Genet Metab. 2006;88:71.

18. Murphy RT, Thaman R, Blanes JG. Natural history and familial characteristics of isolated left ventricular non-compaction. Eur Heart J. 2005;26:187.

19. Vatta M, Mohapatra B, Jimenez S. Mutations in cypher/ZASP in patients with dilated cardiomyopathy and left ventricular non-compaction. J Am Coll Cardiol. 2003;42:2014.

20. Bione S, D'Adamo P, Maestrini E, Gedeon A K, Bolhuis P A, Toniolo D. A novel X-linked gene, G4.5. is responsible for Barth syndrome. Nat Genet. 1996;12:385- 9.

21. Ichida F, Tsubata S, Bowles KR. Novel gene mutations in patients with left ventricular noncompaction or Barth syndrome. Circulation. 2001;103:1256-63.

22. Ichida F, Hanamichi Y, Miyawaki T. Clinical features of isolated noncompaction of the ventricular myocardium: longterm clinical course, hemodynamic properties, and genetic background. J Am Coll Cardiol. 1999;34:233-40.

23. Sasse-Klaassen. Ventricular myocardium in the adult is an autosomal dominant disorder in the majority of patients. Am J Med Genet. 2003;119A:162-7.

24. C Lofiego, E Biagini, F Pasquale.Wide spectrum of presentation and variable outcomes of isolated left ventricular noncompaction. Heart. 2007;93:65-71.

25. Ritter M, Oechslin E, Sutsch G. Isolated noncompaction of the myocardium in adults. Mayo Clin Proc. 1997;72:26-31.

26. Duru, F, Candinas, R. Noncompaction of ventricular myocardium and arrhythmias. J Cardiovasc Electrophysiol. 2000;11:493.

27. Yasukawa K, Terai M, Honda A. Isolated noncompaction of ventricular myocardium associated with fatal ventricular fibrillation. Pediatr Cardiol. 2001;22:512-4.

28. Salerno JC, Chun TU, Rutledge JC. Sinus Bradycardia, Wolff Parkinson White, and Left Ventricular Noncompaction : An Embryologic Connection? Pediatr Cardiol. 2008;29:679.

29. Elias J. Isolated non-compaction of the myocardium. Arq Bras Cardiol 2000;74:253-61.

30. Petersen SE, Timperley J, Neubauer S. Left ventricular thrombi in a patient with left ventricular non-compaction in visualisation of the rationale for anticoagulation. Heart. 2005;91:e4

31. Stollberger C, Finsterer J, Blazek G. Left ventricular hypertrabeculation/noncompaction and association with additional cardiac abnormalities and neuromuscular disorders. Am J Cardiol. 2002;90:899-902.

32. Kohli SK, Pantazis AA, Shah JS. Diagnosis of left-ventricular non-compaction in patients with left-ventricular systolic dysfunction: time for a reappraisal of diagnostic criteria? Eur Heart J. 2008;29:89.

33. Agmon Y, Connolly HM, Olson LJ, et al. Noncompaction of the ventricular myocardium. J Am Soc Echocardiogr. 1999;12:859-63.
34. Song ZZ. Echocardiography in the diagnosis left ventricular noncompaction. Cardiovasc Ultrasound 2008;6:64.

35. Engberding R, Bender F. Identification of a rare congenital anomaly of the myocardium by two-dimensional echocardiography: persistence of isolated myocardial sinusoids. Am J Cardiol. 1984;53:17-33.

36. Jenni R, Oechslin EN, Van der Loo B. Isolated ventricular noncompaction of the myocardium in adults. Heart. 2007; 93:11-5.

37. Fazio G, Novo G, D'angelo L, Visconti C, Sutera L, Grassedonio $\mathrm{E}$, et al. Magnetic resonance in isolated noncompaction of the ventricular myocardium. Int J Cardiol. 2008 Dec 24. [Epub ahead of print]

38. Duncan RF, Brown MA, Worthley SG. Increasing Identification of Isolated Left Ventricular Non-Compaction with Cardiovascular Magnetic Resonance:A Mini Case Series Highlighting Variable Clinical Presentation. Heart Lung Circ. 2008;17:9-13.

39. Dodd JD, Holmvang G, Hoffmann U. Quantification of left ventricular noncompaction and trabecular delayed hyperenhancement with cardiac MRI: correlation with clinical severity. AJR Am J Roentgenol. 2007;189:974.

40. Conces DJ, Ryan T, Tarver RD. Noncompaction of ventricular myocardium: CT appearance. AJR Am J Roentgenol. 1991;156:717-8.

41. Daimon Y, Watanabe S, Takeda S. Two-layered appearance of noncompaction of the ventricular myocardium on magnetic resonance imaging. Circ J. 2002 Jun; 66(6):619-21.

42. Hany TF, Jenni R, Debatin JF. MR appearance of isolated noncompaction of the left ventricle. J Magn Reson Imaging. 1997;7:437-8.

43. Soler R, Rodriguez E, Monserrat L. MRI of subendocardial perfusion deficits in isolated left ventricular noncompaction. J Comput Assist Tomogr. 2002;26:373- 5.

44. Junga $G$, et al. Myocardial ischemia in children with isolated ventricular non- complaction. Eur Heart J. 1999;20:910-6.

45. Peterson SE, Selvanayagam JB, Weissman F. Left ventricular non-compaction: insights from cardiovascular magnetic resonance imaging. J Am Coll Cardiol. 2005;46:101-5.

46. Jenni R, Goebel N, Tartini R. Persisting myocardial sinusoids of both ventricles as an isolated anomaly: echocardiographic, angiographic, and pathologic anatomical findings. Cardiovasc Intervent Radiol. 1986;9:127-31.

47. Rigopoulos A, Rizos IK, Aggeli C. Isolated left ventricular noncompaction: an unclassified cardiomyopathy with severe prognosis in adults. Cardiology. 2002; 98:25-32.

48. Toyono M, Kondo C, Nakajima Y. Effects of carvedilol on left ventricular function, mass, and scintigraphic findings in isolated left ventricular non-ompaction. Heart. 2001;86: e4-e6.

49. Stamou SC, Lefrak EA, Athari FC. Heart transplantation in a patient with isolated noncompaction of the left ventricular myocardium. Ann Thorac Surg. 2004;77:1806.

50. Kovacevic-Preradovic T, Jenni R, Oechslin EN. Isolated left ventricular noncompaction as a cause for heart failure and heart transplantation: a single center experience. Cardiology. 2009;112:158

51. Wald R, Veldtman G, Golding F, Kirsh J, McCrindle B, Benson L. Determinants of outcome in isolated ventricular noncompaction in childhood. Am J Cardiol. 2004;94:1581-2. 